\title{
Editing Effects on Generic Moves and Thematic Progression Patterns in Research Article
}

\author{
${ }^{1}$ Farahman Farrokhi, ${ }^{2}$ Dr. Ansarin, ${ }^{3}$ Assef Khalili, PH.D Candidate \\ ${ }^{1}$ Professor in ELT Department, Tabriz University, Tabriz, Iran \\ ${ }^{2}$ Associate Professor, ELT Department, Faculty of Foreign Languages and Literature, Tabriz \\ University, Tabriz, Iran \\ ${ }^{3}$ ELT Department, Faculty of Foreign Languages and Literature, Tabriz University, Tabriz, Iran \\ khaliliasaf@gmail.com
}

\begin{abstract}
Conscious teaching of generic conventions has long been emphasized in the teaching of Scientific Writing in ESP classes both in theory and practice; however, despite all the significance attached to Theme in theory, there does not seem to be a corresponding emphasis, in practice, on Theme or the notion of thematic progression (TP) as an important element affecting cohesion and coherence of monologic texts. Moreover, most works done in the field of ESP have tended to focus on native-speaker (NS) productions, with scant attention given to non-native speaker (NNS) manuscripts, and the editing process that such manuscripts usually require. This is what we tried to do in the present work. We chose the introduction sections of 20 Research Articles (RAs) written by NNS academicians, and contrasted their edited vs. unedited versions in terms of the changes in the rhetorical move structure and TP patterns that the articles are assumed to have undergone in the editing process. It was found that the rhetorical move structure posited by Swales (2004) for article introductions was seldom affected in the editing process while TP patterns were often found to be quite susceptible to different types of editing, with the structural manipulation or corrections having the most effect on the patterns' continuity, often linking back up a sequence of T-units disrupted by inappropriate lexico-grammatical choices in the original drafts. In view of the findings of the present research, it is suggested that consciousness raising on thematization strategies be a necessary supplement to overt teaching of rhetorical moves.
\end{abstract}

Keywords: Generic conventions, rhetorical move, Thematic Progression, thematization, consciousness raising

\section{INTRODUCTION}

Genre knowledge and generic features, along with thematization preferences, and the patterns of Thematic Progression (TP) have long been recognized as important resources, influencing the quality of writing in general and academic writing in particular. The notion of genre has been interpreted differently in different schools which have largely emerged to meet particular requirements associated with particular situations, with each school having its characteristic understanding of and approaches to teaching generic forms in the best possible way suiting their context. Two rough categorization of different genre schools might be the rhetorical and the linguistic genre studies(Bawarshi et al. 2010), the former lacking explicit pedagogical framework, emphasizing immersion like programs for the teaching of 'genre', with the latter (ESP, SFL approaches) emphasizing explicit teaching of generic conventions. The notion of Theme has also been interpreted differently in its own turn, leading to different definitions and identification criteria, with the Systemic Functional Linguistics (SFL) frequently being the common point of reference in modern discourse analysis. There have been extensive theorization about the contribution of Theme to textual development or texture (Halliday 1985, 2004, Hasan et al. 1997), but there have been comparatively less practical work exploring the implications of thematic development and its contribution to the overall structure of academic writing, or Research Articles(RAs), e,g, Gosden (1993). Nor is there much pedagogically oriented work on TP patterns as proposed by Danes (1974) in the literature, or the pedagogical implications of thematic analysis in writing RAs in general. Even the scant attention given to these areas has almost always been directed towards NS productions, trying to extract patterns for NNS to follow. However, there has been virtually no systematic attention given to RAs produced by NNS which often require some editing to be considered for publication, and the editing process which is acknowledged as an important process (Bhatia 1997, Berkenkotter \& Huckin 1995), potentially influencing both generic features and thematic selections have almost been left unexplored. The purpose of the present research 
is to explore the possible relationships that might exist between rhetorical moves and the TP patterns employed within these moves and to focus on the changes that the RAs produced by NNS undergo in terms of the rhetorical moves in the 'Introduction' section of RAs, and the TP patterns employed within these moves.

\subsection{Literature Review}

There might potentially be a lot of camps or schools offering tentative definitions of the concept of 'genre', yet at the level of the present work we might as well draw on the useful and practical classification of genre schools offered by Hyon in her 1996 TESOL Quarterly article. She separated genre theorists and practitioners into three camps: the Sydney School, based on the Systemic Functional Linguistics work of Halliday (1985), which has developed research and well-established pedagogies at a number of academic levels (see e.g., Christie, 1991; Feez, 2002); the English for Specific Purposes (ESP)camp, whose most famous exponent, John Swales, is internationallyrecognized for Genre Analysis (1990) and "moves" in research article introductions; and The New Rhetoric (NR) group, principally North Americans, for whom genre knowledge has been considered to be primarily social, embedded in the community and context of writer and audience (See e.g., Freedman \& Medway, 1994). The first two of these camps are also referred to as linguistic approaches because of their emphasis on conscious teaching of generic conventions, contrasted against the rhetorical approaches which disapprove of consciousness raising in the teaching of generic norms and conventions. Bawarshi et al. (2010) elabaorating on the difference between linguistic and rhetorical genre studies observe "... while ESP genre scholars have tended to understand genres as communicative tools situated within social contexts, Rhetorical Genre scholars have tended to understand genres as sociological concepts mediating textual and social ways of knowing, being, and interacting in particular contexts. In Rhetorical Genre Studies, understanding contexts (and their performance) is both the starting point of genre analysis and its goal"'(p.59). If there is a single point these apparently different approaches to 'genre' have in common, it might be the conviction that genre is essentially tied to a situation.

As Freedman (2006, p.104) observes, both(linguistic and rhetorical approaches) are aware of the limitations of traditional conceptions of genres which focused only on recurring textual features, and both stress the need to recognize the social dimensions of genre. And that the addressee, the context, and the occasion are all emphasized in these traditions. If this much can be taken as the common ground among the three traditions above, the points from which divergences begin must basically have to do with the attempts to tailor the construct of genre to meet the demands of a particular situation from which a particular tradition has originated. For instance, the rhetorical approaches, essentially developed for L1 teaching, including rhetoric, compositions studies, and professional writing, have generally been known to lack explicit instructional frameworks for teaching students about the language features and functions of academic professional genres. It is not difficult to imagine with so few lexico-grammatical errors surfacing in L1 teaching, which obviates the need to focus on form, the classrooms in this approach have generally been considered hardly appropriate places for teaching genre knowledge, as Hyland (2002, p.114) puts it in this approach classrooms are essentially viewed as "inauthentic environment lacking the conditions for complex negotiation and multiple audiences". The proponents of this approach have, instead, suggested term immersion for teaching 'genre knowledge'.

On the contrary, linguistic approaches, initially proposed to help linguistically disadvantaged students, allow explicit teaching of generic conventions in the classroom, and have such a focus incorporated into their pedagogies. For example, Swales (1990) identifies three major moves in RAIs, namely 1. Establishing a territory 2. Establishing a niche and 3. Occupying the niche and their related steps, which, he believes, have to be explicitly taught in ESP classes alongside their related steps. In his later work, Swales (2004) introduces "recycling of increasingly specific topics" for realization of move 2 and 1, trying to enhance the generalizability of his model. It has to be added, however, that even within these linguistic approaches, because of the difference in the target learners (children of minority groups in SFL/ international students in ESP), there are differences of views as to which genres might yield the best results in the classroom.

Obviously, when the goal is to teach academic writing to NNSs in an EFL context, the realistic options open to the teacher are not too many; the teacher will have to explicitly teach the generic conventions of the target genre, i.e. RA structure, and illustrate other relevant linguistic aspects, in an 
attempt to help the students attain a functional command over these resources and use them for the expression of their purposes. The explicit teaching usually takes the form of presentation and practice of regular, recurring patterns of text usually referred to as move, along with notes on general tendencies on the linguistic realization of these moves. After all, as Swales (1990) notes since moves perform different rhetorical functions, they require different linguistic resources to realize those functions (Swales, 1990). There have already been various attempts to outline some general guidelines on such linguistic features which can provide tangible benefits for the students adhering to them. For instance, Knwogu (1997) tries to establish links between the moves and the tense choices or other structural properties associated with these moves, or Gosden (1993) who proposes that the thematization of certain types of information according to the genre is one means through which writers can achieve local discourse goals, for example, the signaling of moves within sections.

However, the true potential of Thematization as a useful resource in ESP classes might be realized if the thematic analysis is carried out, rather than in isolated sentences, in a stretch of discourse with the focus on thematic progression (Danes, 1974), that is, how thematic/rhematic material is linked to the material which comes next in the text. Despite all the significance attached to Theme and its pivotal role in discourse organization and creation of coherence and cohesion in theory, there is surprisingly little research exploring the actual use of this textual resource in actual language use. And there is virtually no research exploring how the thematization strategies employed by a NNS might actually differ from the established norms, and whether or not they undergo changes in the editing process.

\subsection{Definition and Identification of Theme}

The concept of theme is by no means new, if anything, it predates that of Subject, but the renewed interest in Theme in the works on discourse analysis can be credited to the SFL school, which in contrast to formal grammar, tried to provide a functional account of the discourse in operation within the three macro-functions it introduced. However, in spite of the whole array of works inspired by a functional view of texts, it is obvious that SF linguists lack clarity in their discourse on theme. This vagueness is apparent both in definition and identification criteria of Theme. The mainstream SFL subscribe to Halliday's definition of the concept as "the point of departure for what the speaker is going to say," (1985, p.36). This definition is said to be a separating approach (Fries 1992) to the definition of Theme in that it abstracts only the second of Mathesius (1939) 'combining' definition of Theme, who defines Theme as (i) 'that which is known or at least obvious in the given situation' and (ii) that 'from which the speaker proceeds'- that which is known is referred to as Given in SFL.

These definitions, whether separating or combining, have been shown to be not quite as rigorous or straightforward as they may sound, and they may actually produce more definitional problems when they are applied to actual data alongside criteria for Theme identification. The Theme is to be identified by usually being considered to be the clause-initial element, but this apparently simple criterion also produces quite a few problems in practice.

Different meta-functionally differentiated Theme types might co-occur within the same clause in a wide variety of orders, making it difficult to decide exactly where the initial position should begin and end. Halliday (1985) believes the Theme of the clause is the first topical element which has a role in transitivity, but as it will be shown below this identification criterion might have only limited credibility and use- if a clause is being considered in isolation. Obviously, the Theme and its significance and potential can only be appreciated when longer stretches of discourse are considered, or in Hasan et al. (1997, p.xix) term what is semiotically created can only be appreciated in a semiotic environment. And of course there are others, who question the definition and identification of theme provided by the mainstream SFL school.

In short, there seems to be no shortage of views- often contradictory ones- regarding the definition and identification of Theme, with different authors highlighting or overlooking different relevant aspects. As valuable and illuminating as they are at the theoretical plane, such discussions and speculations often get so heated that they seem to have to stay at that plane for ever, yielding few implications for pedagogy. Thus, in the present work which is pedagogically oriented, we have no intention of going over the debates on the criteria for definition or identification of Theme, we will, instead, adopt what we find workable definitions and identification criteria for Theme as provided by (e.g. Downing,1991; Davies, 1997;Ghadessy, 1995) and will try to justify our preference below. We do admit the procedure we are following here is way too far from complete, and is in need of revisions which only the distinguished figures in the field can provide if the they carry on their 
theorizing with a view to offering workable definitions or criteria, which can contribute to actualizing the full potential of Theme in the pedagogical planning and ESP classes.

\subsection{Thematic Progression}

Frantisek Danes proposed the concept of Theme Progression for the first time in 1969 to illustrate the significant role of the theme in the textual development in a systematic way. Putting forward the concept of TP patterns for the first time, Danes states that the organization of information in texts is determined by the progression in the sequence of utterance themes and their corresponding rhemes, and this progression between the successive themes and rhemes which he defines as TP (Danes, 1974). To put it simply, every individual sentence is said to have its own thematic structure made up of its theme and rheme. When used in the context, the thematic structure of each sentence connects to the theme (or rheme) of the sentences preceding or following it in a traceable fashion. This property of the sentence theme to influence and be influenced by the themes (or rhemes) of adjacent sentences is assumed to contribute to the cohesion and coherence(texture) of the text. Danes's model recognizes and tries to demonstrate the significant role that thematic choices play in the overall structuring of discourse, through focusing on the complicated relationship that holds between utterance themes and their related rhemes, defining it as "the choice and ordering of utterance themes, their mutual concatenation and hierarchy, as well as their relationship to the hyperthemes of the superior text units (such as paragraph, chapter), to the whole of text, and to the situation"(Danes, 1974, p.114).

On the basis of his extensive research in massive languages data, Danes(1974) remarks that "Thematic progression might be viewed as the skeleton of the plot"(p.114), and formulates three major patterns of TP: simple linear progression, constant progression, derived hyper-thematic progression.

\subsection{Editing Process}

Despite the fact that the significance of Theme and TP in the development of text is usually recognized, this area is conspicuously underexplored in discourse analysis. The editing process seems to have fared no better in attracting the attention that it deserves from the scholars. Editing which is generally agreed to be a significant process affecting a piece of work considered to belong to a particular genre is surprisingly underexplored in terms of the effects or influences it may exert on the written work. For instance, talking of generic knowledge which he considers to be accessible only to the members of disciplinary communities, Bhatia(1997,p.363) notes that "After peer review, the second most important intervention comes from the editors, who enjoy all the power one can imagine to maintain the identity and integrity of the research article genre." In their study of editorial control to maintain generic integrity, Berkenkotter and Huckin (1995) underscore the significance of editing and editorial control and go so far as to consider the influence of textual activity on a par with the scientific activity in the construction and dissemination of scientific work. Needless to say editing can cover a large domain of editor intervention, ranging from the changing letter-cases, or the use of meta discoursal devices to full structural manipulation of sentences. Our primary focus in the present research will be on the changes that a RA undergoes as manifested in rhetorical moves and TP patterns.

\section{Materials ANd Method}

The 'Introduction' section of 20 Research Articles (RAs) published in Tabriz Journal of Dentistry were selected for the present study. The editor in chief of the journal- a subject expert with an excellent command of English- kindly agreed to share with us the unedited versions of the articles after he was ensured that there would be no references made to the name of the academicians who might have made certain mistakes in the original drafts submitted to the journal. Thus, in a way, our corpus actually consisted of 40 drafts to work on, half (20) of them being the unedited initial drafts, and the other half (20) being the edited published forms of the same RAs. Limitations on the selection of RAs were as follows: the RAs had appeared in 2009-2013 volumes as regular papers. The primary criterion for inclusion in the corpus was the papers having the standard format of IMRD, and the papers which did not have this format, e.g. case reports were not included. Also an attempt was made to pick the articles whose unedited drafts seemed to include the most mistakes so that our corpus would constitute a more representative sample of the linguistic problems that our academicians have when they write in English. Because of these imposed limitations, the procedure for selection of the 20 RAs was thus not as random as outlined by Crookes (1986). However, as refereed, published articles, these NNS products of a highly conventionalized genre may be taken as representative of the problems experienced by NNS academicians when they write in English. 
Almost all authors, as academic staff members, were supposed to have successfully completed at least one of the compulsory ESP courses on RA writing. Even then, however, some divergence from the established norms was expected to be observed in the manuscripts as our data were all products of NNS, and the editor, though indisputably highly proficient in English-was also a NNS.

First, the rhetorical moves in the two drafts were identified on the basis of the communicative functions they served in accordance with Swales (2004) model for RAIs, which seemed to be accommodating the reality of our data more neatly than its predecessors (e.g. 1981, 1990).

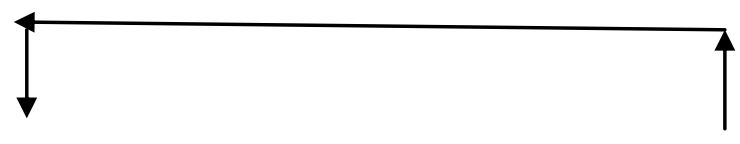

Move 1 Establishing a territory (citation required)

Via

Topic generalizations of increasing specificity

Move 2 Establishing a niche (Citations possible)

Via

Step 1A Indicating a gap

or

Step 1B Adding to what is known

Step 2 Presenting positive justification

(optional)
(Possible

recycling of

increasingly

specific topics)

\section{Move 3 Presenting the present work (citation possible)}

Adapted from Swale's (2004) revised CARS model pp. 230-232

A possible reason for Swales 2004 model better fitting our data might well have had to do with the allowance of "possible recycling of increasingly specific topics" which accounts for a sizable portion of the sentences in moves 2 , and 3 in our data, which would have been difficult to allocate into particular moves without this accommodation. Of course, the increasing specificity of the topics was not being strictly observed in our data, which is why we also included "recycling of topics of equal specificity" in table one. It goes without saying that creation of this category cannot mean that we recognize this sort of elaboration on the topic; we only wanted to be able to tell the papers where increasing specificity of the recycled items had been adhered to from those in which it was not.

Once the moves were identified and compared between the ed. Vs. uned. drafts, the T-units inside each move were counted to determine the length of each move in terms of T-units. We tried to establish if there was a discernable pattern of progression among the T-units, using three major patterns of Thematic Progression (TP) posited by Danes (1974,1978), namely1. simple linear progression, 2.constant progression 3.derived hyperthematic progression

1) The first type is "simple linear TP" in which the rhemes are linearly thematized, or the context of theme of 2 nd sentence is derived from the context of rheme of the preceding sentence, the context of theme 3 from the context of rheme 2, etc. as shown below:

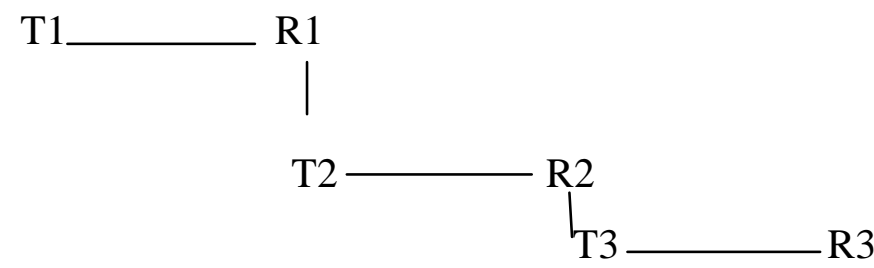

2) the second type of TP which can be called 'theme interaction' refers to a TP with a continuous (constant) theme, provided that themes of at least two adjoining sentences are identical. In this type of TP the same theme enters into relation with a number of different rhemes. The result of this kind of 
TP is that the themes in the text constitute a chain of (typically) co-referential items which extends through a sequence of sentences or clauses.

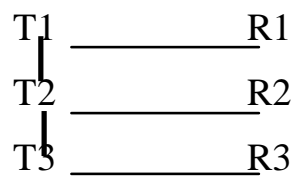

3) The third type is 'TP with derived themes' in which case the themes of individual sentences are derived from the so-called hyper theme of the text. Such instances happen when the whole passage concerns a general notion, and themes of the constituent clauses are all derived from that general notion but are not identical to one another. Derived thematic progression : the Theme of one clause derives from a Hypertheme which is not explicitly found in the immediate context of the Theme in question. In this study, the notion of hypertheme has been altered to include any "theme" that can be said to be hovering about the text, e.g. the title of the article, or the overall Theme of the paragraph, etc. or any Theme that is repeated in sequences of $\mathrm{T}$ units longer than 3.

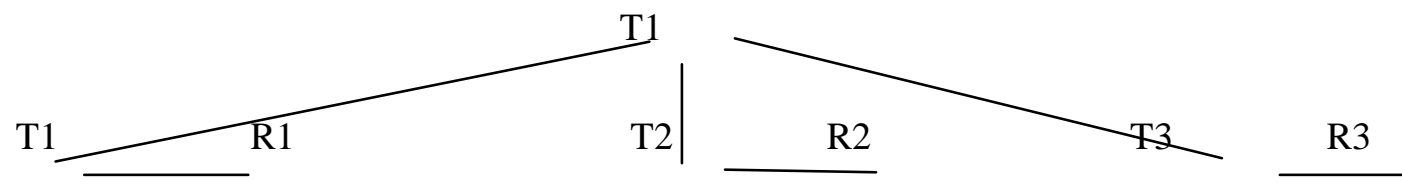

Once TP patterns were drawn for each move on the basis of the three models above, the patterns inside the moves were analyzed to see if a relationship could be established between the TP patterns and particular moves or to see if there was a preference for a particular TP pattern depending on a particular rhetorical purpose. However, our primary concern by far was to investigate if the TP patterns underwent significant changes in the editing process which, we assumed, might have practical implications for pedagogy.

\section{RESUlTS}

The present work was conducted on the Introduction section of 20 RAs, with a view to establishing the characteristics of NNS productions, in terms of the rhetorical moves and TP patterns they employed in their works, investigating the interventions of the editor in these two areas. However, it has to be admitted that a good part of the editor's job was devoted to ironing out of lexicogrammatical errors and punctuation marks, and that the editor did not quite seem to be as meticulous with the rhetorical organization of RAs. When asked why they had not corrected a rather conspicuous deviation e.g. not stating a gap or the research purpose in the introduction sections, the editors responded that they considered those as the reviewer's job. As a matter of fact, it came as a surprise to find out that they were keenly aware of the deviations and the poorly-sequenced moves, yet only occasionally did thy suggest any major changes for the inappropriate structures not grammatically wrong.

\subsection{The Rhetorical Structure}

Considering the nature of our data and our work, it was not unexpected to find that the data did not neatly lend themselves to the models proposed by Nwogu (1997) or Swales (1981, 1990, 2004). However, Swale's revised model of 2004, seemed to be far better suited for the data at hand, probably thanks to "recycling of increasingly specific topics", which was frequently found to be the writers' preferred way of realizing Moves 1 and 2.

\subsection{Move One: Establishing a Territory}

This move, as one would intuitively expect, was present in all research articles for the obvious reason that before you can say anything, you have to set the proper ground for it. However, the length of the move varied rather widely across the papers in our study, normally comprising somewhere between $1 / 3$ to $2 / 3$ of the total number of sentences in the move. Swale's 2004 model seemed to be the best-fitting of the 3 models he's proposed for the structure of RA introductions. The 'Recycling of Increasingly Specific Topics' (RIST) seemed to be the major factor leading to the variation in length of this move, and at times blurring the demarcating line between the first and the second moves both of which could be realized through recycling of increasingly specific topics.

However, even though "recycling of increasingly specific topics" (ROIST) is considered a legitimate strategy for the realization of Moves 1 and 2, and it was almost always resorted to by the writers in 
our data (in 19 out of 20 papers), only in about one third of the papers (papers: 1,2,5,6, 16, 19, 20) was there a discernable chain of specificity going all the way down to the expression of the specific topic of the research (Table 1). In the rest of the papers (except 18 which had not taken this step) the writers were found to be more like elaborating on or wondering, if you will, around the topic, talking about different closely related topics of more of less equal weights. In order to discriminate between these two different ways of narrowing down on the topic and mere extending the topic, we coined the MISSTEP "recycling of items of equal specificity" (RIOES) to refer to the latter. Furthermore, the requirement of citation was hardly consistently observed in the first move, either. Most writers did cite other works, but by no means all.

\subsection{Move 2 'Establishing a Niche'}

was definitely the longest of all the three moves in terms of the T-units used in it, and perhaps partly for that reason, it contained the highest density of editors' work. This is the move where the writer of an RAI, in Swale's words, endeavors to reestablish the significance of the research field itself in the eyes of the discourse community, and to situate the actual research in terms of that significance (Swales, 1990, p.142).

\subsection{Move 3 'Occupying the Niche'}

The third move is by far the shortest of the three, often having a contextualizing element 'in this study' signal its beginning. Its realization usually took one or two T-units, and only rarely were there more than two T-units in this move. This move is actually the culmination of the second move, and if the second was well developed and successfully staged, this move seemed to be better articulated. This move and the need for its mentioning was obviously recognized by the author, but on a few occasions ( 2 articles in our data), when this move had been overlooked the editors did not try to make the necessary correction on the ground that it had to be dealt with by the reviewers- perhaps a misunderstanding that has to be addressed in future.

Table1. T-units identified in the three moves of RAIs and their steps

\begin{tabular}{|c|c|c|c|c|c|c|c|c|c|}
\hline & & 1 & 2 & 3 & 4 & 5 & 6 & 7 & 8 \\
\hline \multirow{3}{*}{ Establishing a Territory } & S1: Background and Topic Generelization & T1-T7 & T1-T3 & & T1-T7 & T1 & & T1 & $\mathrm{T} 1-\mathrm{T} 2$ \\
\hline & & & & T1-T4 & T8-T12 & & T1-T5 & $\mathrm{T} 2-\mathrm{T} 8$ & T3-T5 \\
\hline & S2: ROIST & & T4-T9 & & & $\mathrm{T} 2-\mathrm{T} 4$ & & & \\
\hline \multirow{4}{*}{ Establishing a Niche } & S1 : ROIST & T8-T11 & T10-T16 & & & T5-T14 & T6-T13 & & \\
\hline & ROEST & & & T5-T11 & T23-T26 & & & T12-T24 & $\mathrm{T} 16-\mathrm{T} 25$ \\
\hline & S2: Adding to what is known & & & & T13-T22 & & & T9-T11 & T6-T15 \\
\hline & S3: Gap & $\mathrm{T} 12$ & & T12 & & T15-T16 & T14 & & T26-T28 \\
\hline Occupying the Niche & S1: Presenting the present work & T13-T15 & T17 & No purpose & \begin{tabular}{|l|} 
T27-T28 \\
\end{tabular} & T17 & T15 & $\mathrm{T} 25$ & No Purpose \\
\hline
\end{tabular}

\begin{tabular}{|c|c|c|c|c|c|c|c|c|}
\hline & & 9 & 10 & 11 & 12 & 13 & 14 & 15 \\
\hline \multirow{3}{*}{ Establishing a Territory } & S1: Background and Topic Generelization & T1-T6 & T1-T3 & T1-T3 & T1-T5 & T1-T4 & T1-T6 & T1-T3 \\
\hline & & & & & & & & \\
\hline & S2: ROIST & & & & & & & \\
\hline \multirow{4}{*}{ Establishing a Niche } & S1: ROIST & & & & & & & \\
\hline & ROEST & T14-T23 & T4-T8 & T7-T13 & T11-T22 & T5-T10/T16-T22 & T10-T12 & T4-T11/T12-T18 \\
\hline & S2: Adding to what is known & T7-T13 & & T4-T6 & T6-T10 & T11-T15 & T7-T9 & \\
\hline & S3: Gap & T24-T25 & & T14-T15 & & & & \\
\hline Occupying the Niche & S1: Presenting the present work & T26-T27 & T9 & T16 & T23 & T23 & T13-T14 & T19-T20 \\
\hline
\end{tabular}

\begin{tabular}{|c|c|c|c|c|c|c|}
\hline & & 16 & 17 & 18 & 19 & 20 \\
\hline \multirow{3}{*}{ Establishing a Territory } & S1: Background and Topic Generelization & T1-T5 & T1-T5 & T1-T3 & & T1-T4 \\
\hline & & & & & & \\
\hline & S2: ROIST & & & & T1-T3 & \\
\hline \multirow{4}{*}{ Establishing a Niche } & S1: ROIST & T6-T15 & & & T4-T10 & T11-T26 \\
\hline & ROEST & & T8-T20 & & & \\
\hline & S2 : Adding to what is known & & T6-T7 & T4-T9 & & $\mathrm{T} 5-\mathrm{T} 10$ \\
\hline & S3: Gap & T16-T17 & T21-T23 & $\mathrm{T} 10$ & $\mathrm{~T} 11$ & \\
\hline Occupying the Niche & S1: Presenting the present work & T18 & T24 & T11 & T12-T15 & T27 \\
\hline
\end{tabular}

\subsection{Thematic Progression in the Three Moves in (Un) Edited Drafts}

Within the RAIs, the TP patterns were discernable within the first two moves in the original (unedited) drafts produced by the writers although it was difficult to establish a direct association between a particular TPP and the communicative purpose of a move in which the pattern was 
identified. However, there did seem to be a kind of connection between the overall quality and organization of the article (as judged by the editor and the amount of editing a paper required) and the systematicity of the TPPs identified in it, an observation which is indicative of the significant role that Theme and TPPs play in the overall texture of a text. In other words, Danes' view of TP as the skeleton of the plot $(1974$, p. 114) or Halliday emphasis on the fundamental role that thematic selection plays in organizing discourse (1985, p. 62), both seem to be borne out even in the manuscripts of NNSs. Admittedly, the systematicity of the TP patterns in our data might not have been at the level of NS products (Khalili 2011), but all three patterns of progression posited by Danes (1974) were readily visible in the well-written articles. Most often, more than one pattern type was found to have been used by the writers, with the first two patterns, namely the linear progression and constant Theme iteration being the dominant ones. As for the papers which called for a lot of editing, the structural manipulations affecting the GS of the sentences frequently lead to the emergence of TP patterns. We are not drawing the patterns of progression here for space considerations, but the full list differentiating between the TPPs identified in the original drafts and those emerging after editing will be provided in the appendix.

In addition to TPPs observed in the original drafts of higher quality- which were seldom affected in the editing process, there were some patterns that emerged after the editing process. The mere fact that there are TPP emerging after editing is assumed to be a particularly noteworthy finding. That is where there was structural editing involved as in RAs 3,4,5,7,9,10,11,12,13,14, (in 11 out of $20 \mathrm{RAs}$ ), it frequently seemed to either create or mend a disturbed chain of progression in the thematic selections. In other words, where the writers' products admitted of a structural change (e.g. an active voice construction being changed to passive voice) the ramification of this editing frequently served to strike a cohesive link in the broken line of progression of the themes. Of course, we have to remember that part of this influence on the TP patterns might be accounted for by our definition of Theme herethe elements up to an including the GS. Yet, even though it might partly explain TP pattern sensitivity to structural manipulations, but it may not explain why the structural manipulations served to create or link a sequence of related Themes, and thus it cannot take much a way from the significance of TP patterns in the development of discourse. The TPP that emerged after the editing process were just as varied as those in the original drafts. Consider a few examples below; for example, having been edited, paper eleven begins with a linear progression in the first move, and changes to hyper thematic progression in the second move for as far as $3 \mathrm{~T}$-units before it goes back to the linear progression again,

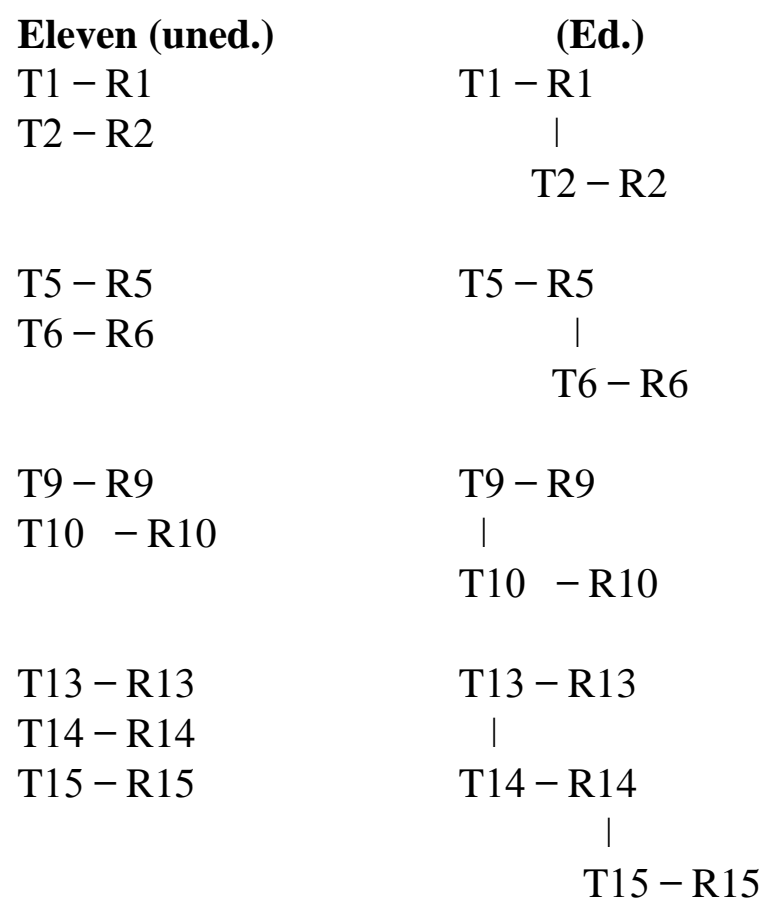

Figure1. TP patterns emerging after editing in paper 11

or in paper 12 the patterns of progression almost alternate between constant and hyper-thematic progression patterns. 


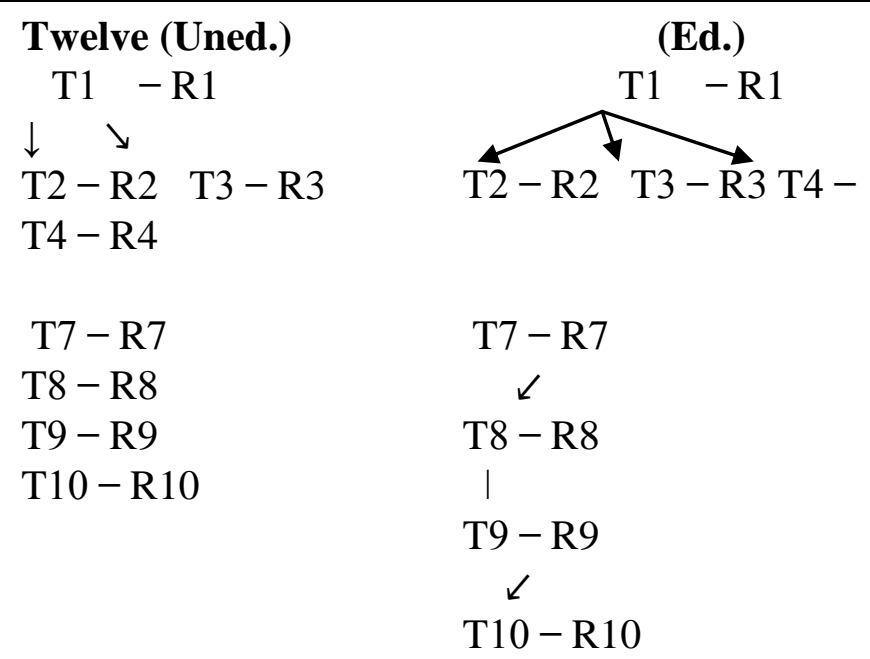

Figure2. Different TP patterns emerging after editing in paper 12

Since thematic choices, whether made by a writer or editor, are largely subconscious, the fact that the editing process brought about such a change does not seem to be a coincidence after all. When an NNS manuscript calls for editing, if anything, the editing process is assumed to improve the texture of the text and enhance the readability. Considering the effect that this process exerts on the TP patterns, it might be safe to conclude that the central role ascribed to the thematic development in text organization in theory is definitely not an overstatement. The implications of this finding for the ESP classes seems obvious, but we know of few ESP classes where this has actually received the attention it deserves in practice.

\section{DisCuSSION}

The significance of "consciousness raising" on rhetorical move structure has been emphasized (Swales 1990, p.213), and it seems to be getting its due share of attention in ESP classes. However, despite all the theorization acknowledging the role of Theme or TP in discourse organization (e.g. Halldiay, 1985, Danes 1974,1978), there does not seem to be a matching focus on this notion in practice, at least not in the ESP classes in our country. Part of this mismatch might well have to do with the ambiguity that is almost characteristic of SFL definition of the concepts and the guidelines proposed in this school for its definition and identification seem to be excessively theoretically oriented, with little concern about its possible ramifications for practice in ESP classes. That is why Halliday's criteria for identification of theme, that is the first element in the clause initial position which has a function in the transitivity was not adopted here. Rather, we included the grammatical subject as the essential element for the identification of theme as suggested by various scholars (e.g. Downing, 1991; Davies, 1997; Ghadessy, 1995). This allowed us to capture Topical Theme in a more systematic way, which in turn provided for a more reliable means of tracing the thematic development across the text, given the role that subject plays in such development. Furthermore, as indicated in the literature, in the actual thematic analysis of scientific texts, over two third of the Themes have been found to be conflated with GS (Gosden 1993).

However, we have to admit that, in assigning the Subject and all that precedes it to the category of Theme, we are running the risk of missing out on certain nuances of the text. Because, Halliday and the mainstream SFL argue that if the Subject is not in the initial position in the clause (as it is expected to be in the unmarked case), this has to be taken to demonstrate the fact that the writer or speaker has, consciously or unconsciously, chosen to give thematic status to some non-subject element to highlight the role of a particular constituent, or its significance in the structure of the message of text in general. Admittedly, this justification for the choice of the first ideational element as theme seems to be in agreement with common sense and the cornerstone of discourse analysis on the basis of which any variation in the unmarked structure is assumed to be discoursally motivated. Thus, if the enhanced position accorded to a non-subject thematized element is emphasized so much as to the exclusion of the grammatical subject in the boundary of a single sentence, the consequence might be to let the speaker/writer's point be made and his position be duly noted thanks to the thematized item.

However, there is a flipside to this line of argument, too; with everything else following the first ideational element considered as rheme, even the grammatical subject preceded by a pre-posed 
ideational element will be analyzed as rheme. This is no insignificant matter, because being the modally responsible entity (Halliday 1977a,p.183), or the entity by reference to which the proposition can be affirmed or denied .... in respect of which the assertion is claimed to have validity" (Halliday, 1985: 76) are not the only roles GSs can serve in discourse. As Thomas and Hawes (1997) state, "an item in Subject position serves as a more effective prompt for what a passage is about than another item which is not the Subject of the sentence ... This suggests that the grammatical Subject is closely associated with what the message is about" (Thomas and Hawes, 1997:35).

The need to conflate GS with Theme seems even more pressing when one considers the role that is played by Theme in organizing discourse and method of development of text. Since the transitivity elements preceding GS are usually not old information, nor do they indicate the aboutness of the clause, taking these elements as the Theme would seem to contradict the definitions of Theme, distorting the overall picture one could get on the method of development of the text. Finally, by recognizing Theme as the element up to and including the Subject, other elements such as circumstantial Adjunct, which may occur before the Subject in the thematic position, have their enhanced status acknowledged through being classified as Theme along with the Subject. Thus such an interpretation of Theme takes into consideration this loading of ideational elements in the choice of Theme. Thus, this study adopts the position advanced by Davies (1988b, 1997), Ravelli (1995) and Berry (1995), who identify as Theme any ideational element up to and including the Subject.

\section{THEME TYPES IDENTIFIED}

Considering GS as the essential element in our analysis of theme made theme identification quite easy in most cases; however, as Thompson (1996) observes, when analyzing Theme "you will certainly find that you run up against some problems, some more serious than others" (1996:138). Thus, a brief review of the major thematic units encountered in actual research is presented below;

\subsection{Simple Themes}

Simple theme, which is usually called topical Theme is an independent unit, a single transitivity element, which cannot be split; nominal groups, adverbial phrases, interrogative pronouns and verbs can be used as simple themes;

1a. The samples were stored in a saline solution at room temperature for 24 hours.

Ib.Give the second group placebo with ointment $\mathbf{1 c}$.Ceramic materials ${ }^{\mathrm{T}}$ are particularly susceptible to tensile stresses

\subsection{Clause as Theme (Thematic Equative)}

If theme is a clause (namely the clause or the non-finite verbs, such as -ed or -ing phrases), it is called clause as theme.

2a. What the topical application of $0.5 \%$ zinc sulfate resulted in was not unexpected.

2b.The way the mechanical tests were carried out was like that in the previous studies.

\subsection{Multiple Theme}

Generally speaking, simple theme only includes topical theme which relates to the experiential function. However, in addition to the topical theme which must be present, thematic position often gets occupied by meta-functionally differentiated theme types, including textual and interpersonal themes;

3a. In a double-blind randomized controlled study by Khandpur on subacute and chronic eczema, lichen planus and limited psoriasis, topical zinc sulfate $2.5 \%$ in combination with $0.05 \%$ Clobetasol propionate cream (Zincoderm Cream, Apex Laboratories) was found superior to topical steroid use alone

3b. However, in certain studies on healing processes of ulcers, probablythe role of trace elements ${ }^{T I}$, such as zinc, has not been sufficiently examined.

However is a textual theme, in certain studies on the healing process of ulcers, is a circumstantial adjunct and probably is an interpersonal Theme all of which have piled up before the topical Theme the role of trace elements, collectively functioning as the theme of this sentence.

The advantage of including GS as the necessary element in the structure of the Theme becomes more apparent in the context of such sentences especially when thematic development of the text is also 
being studied. If one were to take the first transitivity element as the Theme of the sentence, he would have to stop at the circumstantial adjunct above which is acting as a contextual frame for the expression of the message to be expressed later, rather than as the point of departure of the message in the sentence above.

\subsection{Theme Identification in Orthographic Sentences or Clause Complexes}

Based on Halliday (1994) comment that "the main contribution comes from the thematic structure of independent clauses" (Halliday, 1994:61), and Fries and Francis (1992:47) remark that "the structure of beta clauses, including their thematic structure, tends to be constrained by the alpha clauses", we considered as Rheme any dependent clause which occurred in unmarked order that is followed the main clause in hypotactic constructions.

4a. The increase in strength would be much slower, rendering the cement useless for its intended applications if aluminum was to be removed from such compositions

However, if the dependent clause preceded the independent one, the first clause was analyzed as a marked theme which together with the subject of the following main clause made up an extended theme. Thus, in this study, both the Theme of the clause complex, i.e. the dependent beta clause, and the Theme(s) of the independent alpha clause, i.e. Subject and any marked clause elements preceding it, (including Circumstantial Adjunct Complement, conjunctives and relatives), were considered 'one' Theme, and identified as 'extended Theme. In a like manner, in projecting clauses, the whole projecting clause together with the subject/theme of the projected clause were assumed to constitute an extended theme. No discrimination was made in this regard if there were projecting clauses accompanying any of the clauses referred to above.

\section{4b. When MTA powder is mixed with water, calcium phosphate and calcium oxide are released.}

4c.Although a previous study has shown that hydraulic silicate-based cement has good market in endodontics, the present study confirmed that inflammation in Bio Aggregate group was more severe or equal to Geristore group, especially at 7-, 14-, and 28-day intervals.

4d. It should be considered that although Bio aggregate is a silicate-based cement, lack of trace elements, such as aluminum, might accelerate setting and/or hydration reaction of this kind of cement, with an important role.

Fries and Francis (1992), Berry (1995), , and Davies (1997) and others all argue for the independent clause to be the unit of analysis in a clause complex, and Fries and Francis argue that if one chooses to examine only the 'main' clauses within a clause complex, then it becomes easier to discern the method of development and thematic progression of the text.

In paratactic constructions, however, if the coordinators conjoined two clauses, the related themes were analyzed and counted separately even if the subject of the second was deleted.

5a. The pulp chamber is extremely large with a greater apico-occlusal height than normal (it) and lacks the usual constriction at the cervical region of the teeth with exceedingly short roots.

However, if elements lower than clause level were conjoined by the coordinating conjunctions, only one theme was counted.

5b. Not only the maximum but also the minimum fracture resistance of two groups were more than intra-oral loads.

\subsection{Anticipatory 'it' and existential 'there'}

When these GSs were encountered in the thematic position, they were both labeled 'empty Theme' choices after Quirk, Greenbaum, Leech, and Svartvik (1985). The thematic interpretation of such examples has not been easy for text analysts, for example, Eiler (1986) could offer no text-specific explanation for their occurrences in her study. However, as our work is pragmatically oriented, we simply coded the instances of their occurrence on the basis of the semantic function of the predicated Themes they served to introduce;

6a. There exists a definite statistically significant difference in the mesiodistal width of mandibular canines when measured for males and females.

6b.there was a possibility of trans-gingival contamination......

6c. it was important to strictly observe the time intervals. 
When the so called Empty Themes occurred in dependent clauses they were simply considered part of the subordinate clause and analyzed accordingly.(as explained above)

6d. Since there have been no evdince......

6e. When it was found that ......

Swales (1990,p. 213) argument for "Sensitizing SS to rhetorical effects, that tend to recur in genrespecific texts", and that "consciousness-raising about text structure will turn out to be as important as has been shown to be for grammar" seems to have received the popularity it richly deserves. If anything more than three decades have passed since the introduction of rhetorical moves for RAIs in 1981, and almost all ESP classes around the world recognize the centrality and usefulness of consciousness-raising on the rhetorical moves. Our country is no exception in this regard and almost all writers in our study, who are assumed to have participated in at least one of the often-mandatory courses on academic writing, at least seemed to be trying to adhere to the established move structure in RAIs. This is a point the manuscripts themselves seem to reveal, too. Out of the 20 RAs in our study, only two papers had failed to follow the three moves in RAIs. However, it seems that such an approach, though definitely useful and necessary, is not sufficient - just consider 12 papers in our study (60\% of randomly picked NNS manuscripts) which had only wondered around the topic, apparently trying to recycle 'increasingly specific topics' for the realization of moves 1 or 2 (see table 1). The point we are making here is not to downplay the significance of familiarizing the students with the move structure, rather we believe, in light of the findings of the present research that such training on move structure could best be supplemented through sensitizing SS to the thematic selection they make inside this move.

The finding that thematic selection and progression play pivotal roles in the organization of discourse is by no means new and has long been emphasized by leading figures in the field; Halliday (1985) asserts "the choice of theme has a fundamental role in how discourse is organized- "this means the method of development of texts" Halliday (1985,p.62), and Danes (1978,p.114) calls TP as the "skeleton of the plot". The point we are making here is that the notion of Theme, and TP have not received their fair share of attention in ESP classes as essential resources affecting the quality of discourse, and that their significant role is all but conspicuous even in the RAIs written by NNS. After all, it is not fortuitous that the well written papers in our data (papers: 1,2,5,6, 16, 19, 20) exhibited a tangible cline of specificity in "recycling of increasingly specific topics", together with traceable patterns of TP which were seldom disrupted by the editing process. Furthermore, the papers which had required comparatively more editing, including structural manipulations (as in papers $3,4,5,7,9,10,11,12,13,14)$, the structural editing frequently led to the emergence of new TP patterns which did not exist in the original drafts (see the appendix for the details).

These findings fully support theoretical observations of the distinguished scholars in the field who have underscored the centrality of thematic choices in enhancing the texture of the text, and clearly indicate the direct correlation that exists between the quality of NNS manuscripts, and the traceable TP patterns in their works. As indicated above, TP patterns were already traceable in the highly rated papers by the editors which had required sparse editing, and they did emerge in the other papers with rather intensive editing process involving structural manipulations. The implications of these findings for ESP classes are obvious; alongside the emphasis placed on familiarizing students with the rhetorical organization of different sections of RAs, which has proven to be successful and yielded acceptable results, there has to be a parallel emphasis on the thematic choices made inside the rhetorical moves, and the logical TP patterns that naturally develop if the right choices are made in deciding what elements to give thematic status to.

If this point is duly emphasized in our ESP classes, it is hoped that students could be more scrupulous with their thematization decisions, and be led to make better choices grammatically besides producing texts of enhanced cohesion and coherence.

\section{Conclusion}

Consciousness raising on rhetorical move structure is a practical and effective way of helping students in ESP classes to learn the move structure and incorporate them into their own writing. However, as the NNS manuscripts in our data seemed to reveal this sort of sensitizing students to the move structure, though necessary, may not be sufficient on its own, and consciousness raising on thematic organization and progression might also prove very effective in enhancing the quality of NNS productions. 


\section{REFERENCES}

Artemeva, N., \& Freedman, A. (Eds.). (2006). Rhetorical genre studies and beyond. Inkshed Publications.

Bawarshi, A. S., \& Reiff, M. J. (2010). Genre: An introduction to history, theory, research, and pedagogy. West Lafayette, IN: Parlor Press.

Berkenkotter, C., \& Huckin, T. N. (1995). Genre knowledge in disciplinary communication: Cognition/culture/power. Lawrence Erlbaum Associates, Inc.

Berry, M. (1995). Thematic options and success in writing. Thematic development in English texts, 55-84.

Bhatia, V. K. (1997). Genre-mixing in academic introductions. English for specific purposes, 16(3), 181-195.

Christie, F. (1991). Pedagogical and content registers in a writing lesson. Linguistics and education, 3(3), 203-224.

Crookes, G. (1986). Towards a validated analysis of scientific text structure .Applied linguistics, 7(1), 57-70.

Daneš, F. (1974). Functional sentence perspective and the organization of the text. In F. Daneš (ed.). Papers in Functional Sentence Perspective. Prague: Academia:106-128.., 43-53.

Davies, F. (1988b) 'Reading between the lines: Thematic choice as a device for presenting writer viewpoint in academic discourse.' Especialist 9/1,2: 173-200.

Davies, F. (1997). Marked Theme as a heuristic for analysing text-type, text and genre. Applied linguistics: Theory and practice in ESP, 45-79.

Downing, A. (1991). An alternative approach to theme: a systemic-functional perspective. Word, 42(2), 119-143.

Eiler, M. (1986) 'Thematic distribution as a heuristic for written discourse function' in B. Couture (ed.): Functional Approaches to Writing: Research Perspectives. Norwood, NJ: Ablex.

Feez, S. (2002). Heritage and innovation in second language education. Genre in the classroom: Multiple perspectives, 43-72.

Freedman, A., \& Medway, P. (1994). Locating genre studies: Antecedents and prospects. Genre and the new rhetoric, 1-20.

Fries, P. H., \& Francis, G. (1992). Exploring theme: Problems for research. Occasional Papers in Systemic Linguistics, 6(1992), 45-60.

Fries, P. H. (1995). Themes, Methods of Development, and Texts 'k. On subject and theme: A discourse functional perspective, 118, 317.

Ghadessy, M. (Ed.). (1995). Thematic Development of English Texts. A\&C Black.

Gosden, H. (1993). Discourse functions of subject in scientific research articles. Applied Linguistics, 14(1), 56-75.

Halliday, M.A.K. (1977a). Text as semantic choice in social contexts. Grammars and Descriptions, edited by Teun A. Van Dijk \& J.S. Petofi, 176-225. Berlin: de Gruyter

Halliday, M.A.K. (1985/1994). An Introduction to Functional Grammar. London: Edward Arnold. Hasan, R., \& Fries, P. H. (1995). Reflections on subject and theme: an introduction. reprinted with corrections: 1997). On Subject and Theme. A discourse functional perspective. Amsterdam, Philadelphia: John Benjamins, págs. xiii-xlv.

Hawes, T., \& Thomas, S. (1997). Tense choices in citations. Research in the Teaching of English, 393-414.

Hyland, K. (2002). 6. Genre: Language, Context, and Literacy. Annual review of applied linguistics, 22, 113-135.

Hyon, S. (1996). Genre in three traditions: Implications for ESL. tesol Quarterly, 693-722.

Khalili, A. (2011). Generic Demands on Developmental Patterns of Themes. In Jalaifar, et. al (ed.), Academic Research Genres in an Asian Context: Shahid Chamran University Press.

Mathesius, Vilem. (1928). On linguistic characterology with illustrations fom modern English. Reprinted (1964) in A Prague School Reader in Linguistics, edited and translated by J. Vachek (ed. \& Tr.), 59-67. Bloomington: Indiana University Press. 
Quirk, R., Greenbaum, S., Leech, G., \& Svartvik, J. (1985). A contemporary grammar of the English language.

Ravelli, L. J. (1995). and an Understanding of Theme'k. On subject and theme: a discourse functional perspective, 118, 187.

Nwogu, K. N. (1997). The medical research paper: Structure and functions. English for specific purposes, 16(2), 119-138.

Swales, J. M. (1981). Aspects of article introductions. Language Studies Unit, University of Aston in Birmingham.

Swales, J. (1990). Genre analysis: English in academic and research settings. Cambridge University Press.

Swales, J. (2004). Research Genre: Explorations and applications. Cambridge: Cambridge University Press.

\section{APPENDIX}

\section{TPP Which Emerged After Editing}

\section{Article Three}

Unedited

$\mathrm{T} 1-\mathrm{R} 1$

$\mathrm{T} 2-\mathrm{R} 2$

$\mathrm{T} 3-\mathrm{R} 3$

T4-R4

\section{Article Four}

Unedited

Edited

$\mathrm{T} 1$ - R1
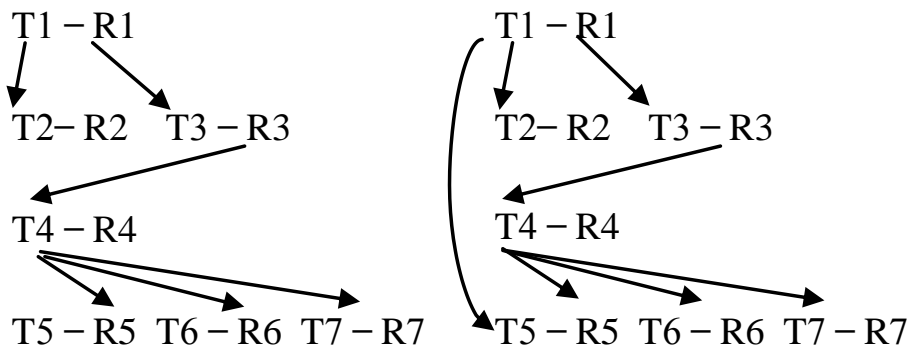

T15 - R15

T16-R16

Article Five

Unedited

Edited

T1 - R1

।

T2- R2

$\mathrm{T} 3-\mathrm{R} 3$

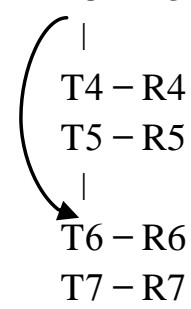

Edited

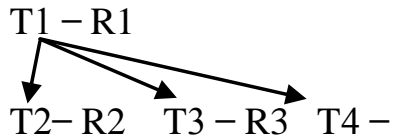



Article Seven
Unedited
T3 - R3
$\mathrm{T} 4-\mathrm{R} 4$
Edited

$$
\begin{gathered}
\mathrm{T} 3-\mathrm{R} 3 \\
\text { ! } \\
\mathrm{T} 4-\mathrm{R} 4
\end{gathered}
$$

\section{Article Nine}

Unedited

T1 - R1

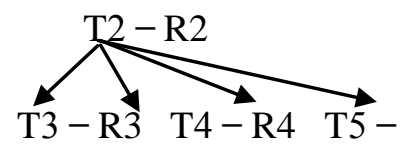

$$
\begin{gathered}
\mathrm{T} 7-\mathrm{R} 7 \\
\mathrm{~T} 8-\mathrm{R} 8 \\
\mathrm{~T} 9-\mathrm{R} 9 \\
C_{\mathrm{T}}^{\mathrm{T} 10-\mathrm{R} 10}
\end{gathered}
$$$$
\text { T11 - R11 }
$$$$
\mathrm{T} 12-\mathrm{R} 12
$$$$
\text { T13-R13 }
$$$$
\text { T14-R14 }
$$$$
\text { । }
$$$$
\text { T15 - R15 }
$$$$
\text { T16-R16 }
$$$$
\text { T17 - R17 }
$$$$
\text { T17 - R17 }
$$$$
\text { T18-R18 }
$$$$
\text { T19-R19 }
$$$$
\text { T20 - R20 }
$$

\section{Article Ten}

Unedited

$\mathrm{T} 1$ - R1

$\mathrm{T} 2-\mathrm{R} 2$$$
\text { I }
$$$$
\text { T3 - R3 }
$$

\section{Article Eleven}

Unedited

T1 - R1

$\mathrm{T} 2-\mathrm{R} 2$

$$
\begin{aligned}
& \text { T5 - R5 } \\
& \text { T6-R6 }
\end{aligned}
$$

\section{Edited}

$\mathrm{T} 1-\mathrm{R} 1$

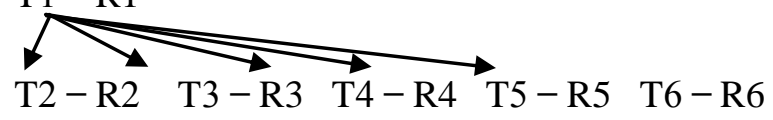

$$
\text { T7 - R7 }
$$

$$
\mathrm{T} 8-\mathrm{R} 8
$$

T

$$
\mathrm{T} 10-\mathrm{R} 10
$$$$
\text { T11 - R11 }
$$
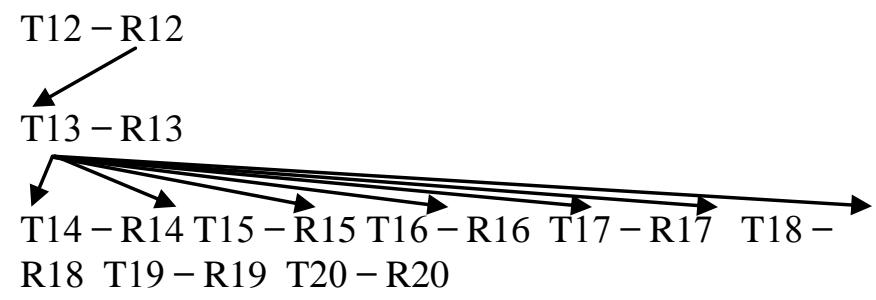


$$
\text { T6-R6 }
$$

$\begin{array}{lc}\text { T9 }-\mathrm{R} 9 & \mathrm{~T} 9-\mathrm{R} 9 \\ \mathrm{~T} 10-\mathrm{R} 10 & \mathrm{~T} 10-\mathrm{R} 10 \\ & \mathrm{~T} 13-\mathrm{R} 13 \\ \mathrm{~T} 13-\mathrm{R} 13 & \text { । } \\ \mathrm{T} 14-\mathrm{R} 14 & \mathrm{~T} 14-\mathrm{R} 14 \\ \mathrm{~T} 15-\mathrm{R} 15 & \text { । } \\ & \mathrm{T} 15-\mathrm{R} 15\end{array}$

Article Twelve

Unedited

Edited

\begin{tabular}{|c|c|c|}
\hline \multicolumn{3}{|c|}{$\mathrm{T} 1-\mathrm{R} 1$} \\
\hline $\begin{array}{l}\downarrow \\
\mathrm{T} 2-\mathrm{R} 2\end{array}$ & $\mathrm{~T}$ & $\Gamma 3-\mathrm{R}$ \\
\hline $\mathrm{T} 4-\mathrm{R} 4$ & & \\
\hline $\mathrm{T} 7-\mathrm{R}$ & & \\
\hline $\mathrm{T} 8-\mathrm{R} 8$ & & \\
\hline $\mathrm{T} 9-\mathrm{R} 9$ & & \\
\hline $\mathrm{T} 1$ & $\mathrm{R} 10$ & \\
\hline
\end{tabular}

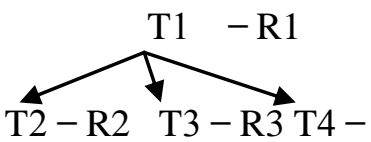$$
\mathrm{T} 7-\mathrm{R} 7
$$$$
\text { K }
$$$$
\mathrm{T} 8-\mathrm{R} 8
$$$$
\text { I }
$$$$
\text { T9- R9 }
$$$$
K
$$$$
\mathrm{T} 10-\mathrm{R} 10
$$ 


\section{Article Thirteen}

Unedited

T5 - R5

T6-R6

$\mid$

T7 - R7

|

$\mathrm{T} 8-\mathrm{R} 8$

T9-R9

$\left.\right|_{\mathrm{T} 10-\mathrm{R} 10}$

T11 - R11

|

$\mathrm{T} 12-\mathrm{R} 12$

$\mathrm{T} 13-\mathrm{R} 13$

T14-R14

T15 - R15

\section{Article Fourteen}

Unedited

T1 - R1

।

$\mathrm{T} 2-\mathrm{R} 2$

।

$\mathrm{T} 3-\mathrm{R} 3$

$\mathrm{T} 4-\mathrm{R} 4$

$\mathrm{T} 5-\mathrm{R} 5$

T6-R6
Edited

T5 - R5

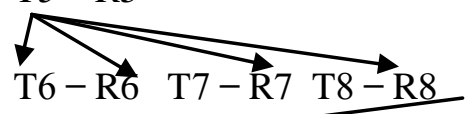

$\mathrm{T} 9-\mathrm{B} 9$

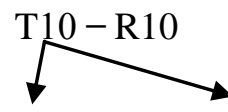

T11 - R11 T12 - R12

|

$\mathrm{T} 13-\mathrm{R} 13$

T14-R14

।

$\mathrm{T} 15-\mathrm{R} 15$
Edited

$\mathrm{T} 1-\mathrm{R} 1$

$\mathrm{T} 2-\mathrm{R} 2$

$\mathrm{T} 3-\mathrm{R} 3$

$\mathrm{T} 4-\mathrm{R} 4$

T5 - R5

T6-R6 
TP Patterns Unaffected in the Editing Process

\begin{tabular}{|c|c|c|}
\hline Article One & Article Two & Article Five \\
\hline $\mathrm{T} 1-\mathrm{R} 1$ & $\mathrm{~T} 1-\mathrm{R} 1$ & $\mathrm{~T} 1-\mathrm{R} 1$ \\
\hline I & I & I \\
\hline $\mathrm{T} 2-\mathrm{R} 2$ & $\mathrm{~T} 2-\mathrm{R} 2$ & $\int^{\mathrm{T} 2-\mathrm{R} 2}$ \\
\hline $\mathrm{T} 3-\mathrm{R} 3$ & I & $\mathrm{T} 3-\mathrm{R} 3$ \\
\hline $\mathrm{T} 4-\mathrm{R} 4$ & $\mathrm{~T} 3-\mathrm{R} 3$ & I \\
\hline I & $\mathrm{T} 4-\mathrm{R} 4$ & $\mathrm{~T} 4-\mathrm{R} 4$ \\
\hline $\mathrm{T} 5-\mathrm{R} 5$ & $\mathrm{~T} 5-\mathrm{R} 5$ & $\mathrm{~T} 5-\mathrm{R} 5$ \\
\hline I & T6 - R6 & I \\
\hline T6 - R6 & I & T6-R6 \\
\hline | & $\mathrm{T} 7-\mathrm{R} 7$ & $\mathrm{~T} 7-\mathrm{R} 7$ \\
\hline $\mathrm{T} 7-\mathrm{R} 7$ & $\mathrm{~T} 8-\mathrm{R} 8$ & $\mathrm{~T} 8-\mathrm{R} 8$ \\
\hline $\mathrm{T} 8-\mathrm{R} 8$ & | & T9-R9 \\
\hline | & $\mathrm{T} 9-\mathrm{R} 9$ & । \\
\hline $\mathrm{T} 9-\mathrm{R} 9$ & I & $\mathrm{T} 10-\mathrm{R} 10$ \\
\hline I & $\mathrm{T} 10-\mathrm{R} 10$ & T11 - R11 \\
\hline $\mathrm{T} 10-\mathrm{R} 10$ & I & | \\
\hline I & $\mathrm{T} 11-$ & $\mathrm{T} 12-\mathrm{R} 12$ \\
\hline $\mathrm{T} 11-\mathrm{R} 11$ & $\mathrm{~T} 12-\mathrm{R} 12$ & I \\
\hline I & $\mathrm{T} 13-\mathrm{R} 13$ & $\mathrm{~T} 13-\mathrm{R} 13$ \\
\hline $\mathrm{T} 12-\mathrm{R} 12$ & I & I \\
\hline I & $\mathrm{T} 14-\mathrm{R} 14$ & $\mathrm{~T} 14-\mathrm{R} 14$ \\
\hline $\mathrm{T} 13-\mathrm{R} 13$ & | & $\mathrm{T} 15-\mathrm{R} 15$ \\
\hline $\mathrm{T} 14-\mathrm{R} 14$ & $\mathrm{~T} 15-\mathrm{R} 15$ & $\mathrm{~T} 16-\mathrm{R} 16$ \\
\hline \multirow[t]{3}{*}{$\mathrm{T} 15-\mathrm{R} 15$} & I & T17 - R17 \\
\hline & $\mathrm{T} 16-\mathrm{R} 16$ & \\
\hline & $\mathrm{T} 17-\mathrm{R} 17$ & \\
\hline
\end{tabular}


Editing Effects on Generic Moves and Thematic Progression Patterns in Research Article

\begin{tabular}{|c|c|c|}
\hline Article Six & Article Sixteen & Article Nineteen \\
\hline$-\mathrm{T} 1-\mathrm{R} 1$ & $\mathrm{~T} 1-\mathrm{R} 1$ & $\mathrm{~T} 1-\mathrm{R} 1$ \\
\hline$\infty$ & | & $\mathrm{T} 2-\mathrm{R} 2$ \\
\hline $\mathrm{T} 2-\mathrm{R} 2 \mathrm{~T}_{3}-\mathrm{R} 3 \mathrm{~T} 4-\mathrm{R} 4$ & $\mathrm{~T} 2-\mathrm{R} 2$ & 1 \\
\hline $\mathrm{T} 6-\mathrm{R} 6$ & $\mathrm{~T} 3-\mathrm{R} 3$ & $\mathrm{~T} 3-\mathrm{R} 3$ \\
\hline $\mathrm{T} 7-\mathrm{R} 7$ & । & । \\
\hline | & $\mathrm{T} 4-\mathrm{R} 4$ & $\mathrm{~T} 4-\mathrm{R} 4$ \\
\hline $\mathrm{T} 8-\mathrm{R} 8$ & | & । \\
\hline | & $\mathrm{T} 5-\mathrm{R} 5$ & T5 - R5 \\
\hline $\mathrm{T} 9-\mathrm{R} 9$ & $\mathrm{~T} 6-\mathrm{R} 6$ & $\mathrm{~T} 6-\mathrm{R} 6$ \\
\hline । & $\mid$ & | \\
\hline $\mathrm{T} 10-\mathrm{R} 10$ & $\mathrm{~T} 7-\mathrm{R} 7$ & $\mathrm{~T} 7-\mathrm{R} 7$ \\
\hline । & $\mathrm{T} 8-\mathrm{R} 8$ & $\mathrm{~T} 8-\mathrm{R} 8$ \\
\hline $\mathrm{T} 11-\mathrm{R} 11$ & | & $\mathrm{T} 9-\mathrm{R} 9$ \\
\hline | & T9-R9 & $\mid$ \\
\hline $\mathrm{T} 12-\mathrm{R} 12$ & $\mathrm{~T} 10-\mathrm{R} 10$ & $\mathrm{~T} 10-\mathrm{R} 10$ \\
\hline $\mathrm{T} 13-\mathrm{R} 13$ & & $\mathrm{~T} 11-\mathrm{R} 11$ \\
\hline $\mathrm{T} 14-\mathrm{R} 14$ & $\mathrm{~T} 11-\mathrm{R} 11 \mathrm{~T} 12-\mathrm{R} 12$ & $\mathrm{~T} 12-\mathrm{R} 12$ \\
\hline \multirow[t]{6}{*}{$\mathrm{T} 15-\mathrm{R} 15$} & $\mathrm{~T} 13-\mathrm{R} 13$ & $\mathrm{~T} 13-\mathrm{R} 13$ \\
\hline & & $\mathrm{T} 14-\mathrm{R} 14$ \\
\hline & $\mathrm{T} 14-\mathrm{R} 14 \mathrm{~T} 15-\mathrm{R} 15$ & $\mathrm{~T} 15-\mathrm{R} 15$ \\
\hline & $\mathrm{T} 16-\mathrm{R} 16$ & \\
\hline & $\mathrm{T} 17-\mathrm{R} 17$ & \\
\hline & $\mathrm{T} 18-\mathrm{R} 18$ & \\
\hline
\end{tabular}




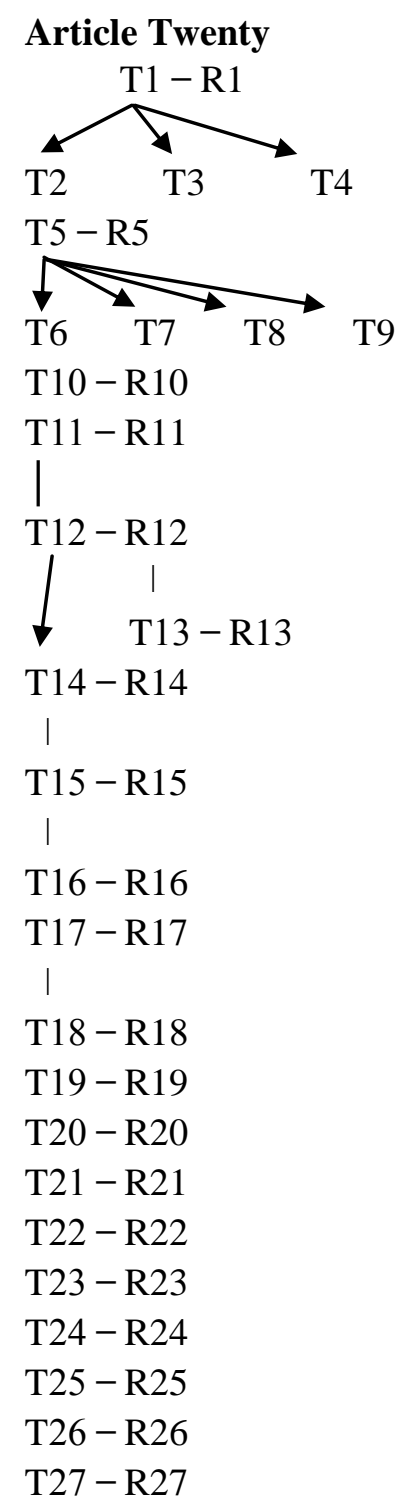

\section{AUTHORS' BIOGRAPHY}

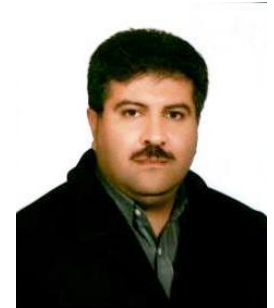

Farahman Farrokhi, Professor, ELT Department, Faculty of Foreign Languages and Literature, Tabriz University, Tabriz, Iran. Head of the ELT Department

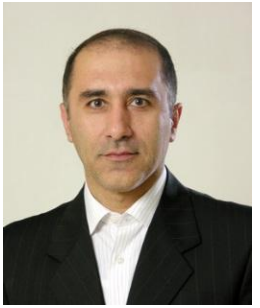

Ali Akbar Ansarin, Associate Professor, ELT Department, Faculty of Foreign Languages and Literature, Tabriz University, Tabriz, Iran.

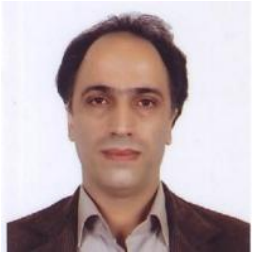

Assef Khalili, Ph.D. Candidate, ELT Department, Faculty of Foreign Languages and Literature, Tabriz University, Tabriz, Iran. Instructor at Tabriz University of Medical Sciences, Tabriz, Iran 